\title{
Effect of individual allergen sensitization on omalizumab treatment outcomes in patients with severe allergic asthma determined using data from the Czech Anti-lgE Registry
}

Petr Vaník ${ }^{1}$, Jakub Novosad ${ }^{2 *}$ (1) Olga Kirchnerová ${ }^{3}$, Irena Krčmová2 ${ }^{2}$ Milan Teřl ${ }^{3}$ and Czech Anti-IgE Registry collaborators

\begin{abstract}
Background: Omalizumab is an efficient drug for patients with uncontrolled severe allergic asthma (SAA). However, little is known about the differences in omalizumab treatment outcomes among patients with different types of atopic sensitization. Here, we assessed the effect of sensitization to individual allergens or their combinations on the outcomes of anti-lgE therapy in patients with SAA.

Methods: We performed a post hoc analysis of data of subgroups of patients enrolled in the Czech Anti-lgE Registry (CAR). The patients were evaluated at baseline and 16 weeks and 12 months after omalizumab treatment initiation. We analyzed the dependence of primary treatment outcomes [global evaluation of treatment effectiveness (GETE) after 16 weeks of treatment, a reduction in severe exacerbation rate (ER), and an improvement in the asthma control test (ACT) result during 12 months of treatment] and secondary outcomes [a reduction in systemic corticosteroid (SCS) use, an improvement in lung functions, and a fraction of exhaled nitric oxide] of patients with SAA treated with omalizumab for 12 months on sensitization to different perennial aeroallergens. We assessed sensitization to house dust mites, molds, and pets at baseline using skin prick tests and/or specific lgE measurement (semiquantitative evaluation). We compared polysensitized patients (sensitized to all tested allergens) with monosensitized (single positivity) or partially polysensitized patients (combined positivity but not to all allergens).
\end{abstract}

Results: We enrolled 279 patients (58.3\% women, mean age 52.9 years). Omalizumab treatment presented an $82.8 \%$ response rate (according to GETE). It significantly reduced severe asthma exacerbations and SCS use, and improved the ACT result in 161 responders. We identified a subgroup of responders with distinct sensitization patterns (polysensitization to all tested perennial allergens) with higher odds of being responders $(O R=2.217, p=0.02$ ) and lower tendency to improve ACT result (OR 0.398, $p=0.023$ ) and reduce ER (OR 0.431, $p=0.034)$ than nonpolysensitized patients.

Conclusions: The clinical benefit of sensitization for patients with SAA receiving omalizumab may be particularly dependent on sensitization pattern. Polysensitized patients showed a higher tendency to be responders (GETE), but a lower tendency to improve the ACT result and reduce ER than non-polysensitized patients.

${ }^{*}$ Correspondence: jakub.novosad@fnhk.cz

${ }^{2}$ Institute of Clinical Immunology and Allergy, University Hospital and Faculty of Medicine, Hradec Kralove, Czech Republic

Full list of author information is available at the end of the article

(c) The Author(s) 2020. This article is licensed under a Creative Commons Attribution 4.0 International License, which permits use, sharing, adaptation, distribution and reproduction in any medium or format, as long as you give appropriate credit to the original author(s) and the source, provide a link to the Creative Commons licence, and indicate if changes were made. The images or other third party material in this article are included in the article's Creative Commons licence, unless indicated otherwise in a credit line to the material. If material is not included in the article's Creative Commons licence and your intended use is not permitted by statutory regulation or exceeds the permitted use, you will need to obtain permission directly from the copyright holder. To view a copy of this licence, visit http://creativeco mmons.org/licenses/by/4.0/. The Creative Commons Public Domain Dedication waiver (http://creativecommons.org/publicdomain/ zero/1.0/) applies to the data made available in this article, unless otherwise stated in a credit line to the data. 
Keywords: Omalizumab, Severe allergic asthma, Allergic sensitization

\section{Background}

The global prevalence of asthma is still uncertain $[1,2]$, and some experts suggest a prevalence of $7-8 \%$ (i.e., 700 000-800 000 people) in the Czech Republic (CR). In this particular asthma population, probably more than $80 \%$ of patients have eosinophilic (or type 2-high) and over $70 \%$ have eosinophilic allergic (or Th2- high) asthma endotype [3-7].

Patients with severe asthma [8] (or severe refractory asthma) account for approximately $2.1 \%$ of the whole asthmatic population in the CR [3]. Currently, the Global Initiative for Asthma (GINA) recommends targeted biological therapy before the administration of systemic corticosteroids (SCSs) in step 5 of the integrated treatment strategy, wherever possible. The broad clinical effects of omalizumab have been extensively documented in controlled studies $[9,10]$ and real-world studies [11-15].

However, little is known about the differences in treatment outcomes associated with a particular sensitization type or combinations of aeroallergens. In general, allergic reactivity to perennial allergens (such as house dust mites, molds, dogs, and cats) must be proved to initiate an anti-IgE monoclonal antibody omalizumab treatment [16]. Nonetheless, a previous study has indicated that sensitization to seasonal allergens can lead to a comparable treatment response [17].

In this study, we aimed to evaluate the potential differences in treatment outcomes among patients with severe allergic asthma (SAA) according to the sensitization pattern to different aeroallergens and their combinations. All patients were treated in accordance with local and international guidelines [7, 18, 19] using high-dose inhaled corticosteroids with long-acting $\beta 2$-agonists or an alternative controller (leukotriene receptor antagonists or theophylline) with an add-on anti-IgE therapy with omalizumab. We used data from the Czech anti-IgE Registry (CAR).

We assessed the following treatment outcomes: (1) responding (according to the global evaluation of treatment effectiveness [GETE] at 16 weeks after treatment initiation), not responding, or withdrawing treatment; (2) a reduction in severe exacerbation rate (ER) after 12 months of treatment in responders compared with that in non-responders and patients who withdrew omalizumab treatment; and (3) an improvement in the asthma control test (ACT) result after 12 months of treatment (in all three study arms) in patients with SAA treated with omalizumab. In addition, we assessed the following secondary outcomes at baseline and after 12 months of treatment in all three study arms: (1) dependence on corticosteroid use, (2) spirometry characteristics (forced expiratory volume in 1 s FEV1), and (3) fraction of exhaled NO (FeNO). Furthermore, all treatment outcomes were analyzed in relation to the sensitization type by different aeroallergens at baseline and compared between polysensitized patients (sensitized to all tested allergens) and monosensitized or partial polysensitized patients. The main aim of the study was to test the hypothesis that different treatment outcomes may be obtained for each sensitization pattern.

\section{Methods \\ Study design}

This study was designed as a multicenter, noninterventional, observational post hoc analysis of longitudinal data of patients enrolled in the CAR in 10 specialized centers [National Centre for Severe Asthma (NCTA)] in the CR between 2007 and 2018. Data analysis had a mixed design (cross-sectional and longitudinal analyses). Data were collected at three time points: baseline and at 16 weeks and 12 months after treatment initiation.

\section{Study sample}

From 389 patients enrolled in the CAR, 279 individuals from the 10 NCTA centers in the CR were analyzed (additional data of individual allergic sensitization were available). All patients had SAA with a proven allergy to at least one (or more) perennial airborne allergen and had $\geq 2$ severe asthma exacerbations [20-22] in the year before omalizumab treatment initiation. Omalizumab treatment was maintained in 161 patients for 12 months. In 118 patients, omalizumab treatment was discontinued (in 48 patients for a lack of efficacy and in 70 patients for other reasons).

\section{Study procedures}

The patients were evaluated by physicians before treatment initiation (baseline) and at 16 weeks and 12 months after omalizumab administration. The clinical evaluation at each visit was performed by spirometry [23] and using the FeNO analysis [24, 25]. In addition, the medical history of patients, with respect to the average dose of SCS in the 4 month before treatment (assessed and expressed as an equivalent of prednisolone), rescue 
medication, and severe asthma exacerbation [22], was recorded, and the patients were requested to complete an ACT questionnaire [26, 27].

At baseline, skin prick test (SPT) and laboratory assessment (total and specific IgE in international units per $\mathrm{ml}, \mathrm{IU} / \mathrm{ml}$ ) were performed in all patients. A positive result in the SPT was defined as a mean wheal diameter of $\geq 3 \mathrm{~mm}$ [28]. All results were categorized as negative (SPT $<3 \mathrm{~mm}$ and/or $\operatorname{sIgE}<0.35 \mathrm{IU} / \mathrm{ml}$ ), mild positive (SPT $<10 \mathrm{~mm}$ and/or $\operatorname{sIgE}<3.5 \mathrm{IU} / \mathrm{ml}$ ), or strong positive (SPT $\geq 10 \mathrm{~mm}$ and/or $\mathrm{sIgE} \geq 3.5 \mathrm{IU} / \mathrm{ml}$ ). In cases of discordance between the SPT and specific IgE, the stronger sensitization result was considered. In the analysis of dichotomous variables, a positive result refers to any SPT and/or sIgE positivity. In our analyses, the "polysensitized" group comprised patients who were concurrently sensitized to all tested perennial allergens, that is, mites, molds, and pets (Table 1).

The GETE analysis was performed by physicians at $16 \pm 1$ weeks. The patients were rated on a five-point scale: 1 , excellent (complete control of asthma); 2 , good (marked improvement); 3 , moderate (discernible, but limited improvement); 4, poor (no appreciable change); and 5, worsening (overall deterioration of asthma control). Patients with an "excellent" or "good" response were considered responders $(n=231)$ and those with a "moderate," "poor," or "worsening" response were considered non-responders $(n=48)$ [29]. Omalizumab therapy was discontinued in non-responders. Some patients who were considered as responders withdrew from therapy $(\mathrm{n}=70)$ for other reasons $(8$ for adverse reactions, 1 for allergy to omalizumab, 13 for non-compliance, 48 for other non-omalizumabdependent reasons). Both these groups of patients underwent another evaluation after 1 year of treatment or at follow-up. The study design is shown in Fig. 1.

\section{Statistical analysis}

All effectiveness variables were analyzed using the per-protocol population, which comprised patients enrolled in the registry. For analyses at specific time points, all patients with available data at that time point were considered for the analysis. Descriptive statistics are expressed as mean with standard deviation (SD) [or as median with inter-quartile range (IQR) in cases of non-normal data distribution] or frequency. For comparisons of two independent samples, we used a two-sample $t$ test or Mann-Whitney test in cases where the assumption of normality was not met. Large numbers of independent samples were analyzed using a one-way ANOVA or Kruskal-Wallis test in cases of non-normal data distribution. Repeated measures were treated using a general linear model for repeated measures (GLM-RM) or Wilcoxon signedrank test in cases of normality assumption violation. In the applicable cases, the standardized effect size characteristics for GLM were reported (partial $\eta^{2}$ ). Frequency was analyzed using the Chi squared test. Binomial dependent variables were treated using logistic regression. Results with a p value of $<0.05$ were considered statistically significant. Data were analyzed using IBM SPSS Statistics for Windows, Version 22.0 (Armonk, NY: IBM Corp).

Table 1 Sensitization characteristics (per-protocol analysis)

\begin{tabular}{|c|c|c|c|c|c|c|c|c|c|}
\hline \multirow[t]{2}{*}{ Sensitization } & \multicolumn{2}{|c|}{ Whole sample } & \multicolumn{2}{|c|}{ Responders } & \multicolumn{2}{|c|}{ Non-responders } & \multicolumn{2}{|c|}{ Withdrew } & \multirow[t]{2}{*}{$p$} \\
\hline & $\mathbf{n}$ & $\%$ & $\mathbf{n}$ & $\%$ & $\mathbf{N}$ & $\%$ & $\mathbf{n}$ & $\%$ & \\
\hline$n$ & 279 & 100.0 & 161 & 57.7 & 48 & 17.2 & 70 & 25.1 & \\
\hline Monosensitization Alternaria & 3 & 1.1 & 2 & 1.2 & 1 & 2.1 & 0 & 0.0 & 0.249 \\
\hline Monosensitization Aspergillus & 12 & 4.3 & 6 & 3.7 & 1 & 2.1 & 5 & 7.1 & \\
\hline Cats and dogs & 22 & 7.9 & 14 & 8. & 4 & 8.3 & 4 & 5.7 & \\
\hline Molds, cats, and dogs & 14 & 5.0 & 8 & 5.0 & 3 & 6.3 & 3 & 4.3 & \\
\hline Molds & 24 & 8.6 & 12 & 7.5 & 4 & 8.3 & 8 & 11.4 & \\
\hline Mites, cats, and dogs & 51 & 18.3 & 31 & 19.3 & 11 & 22.9 & 9 & 12.9 & \\
\hline Mites and molds & 32 & 11.5 & 14 & 8.7 & 4 & 8.3 & 14 & 20.0 & \\
\hline Mites & 70 & 25.1 & 37 & 23.0 & 16 & 33.3 & 17 & 24.3 & \\
\hline Mites, molds, cats, and dogs & 51 & 18.3 & 37 & 23.0 & 4 & 8.3 & 10 & 14.3 & \\
\hline Polysensitization & 51 & 18.3 & 37 & 23.0 & 4 & 8.3 & 10 & 14.3 & 0.043 \\
\hline Non-polysensitization & 228 & 81.7 & 124 & 77.0 & 44 & 91.7 & 60 & 85.7 & \\
\hline
\end{tabular}

Analysis: Chi squared test 


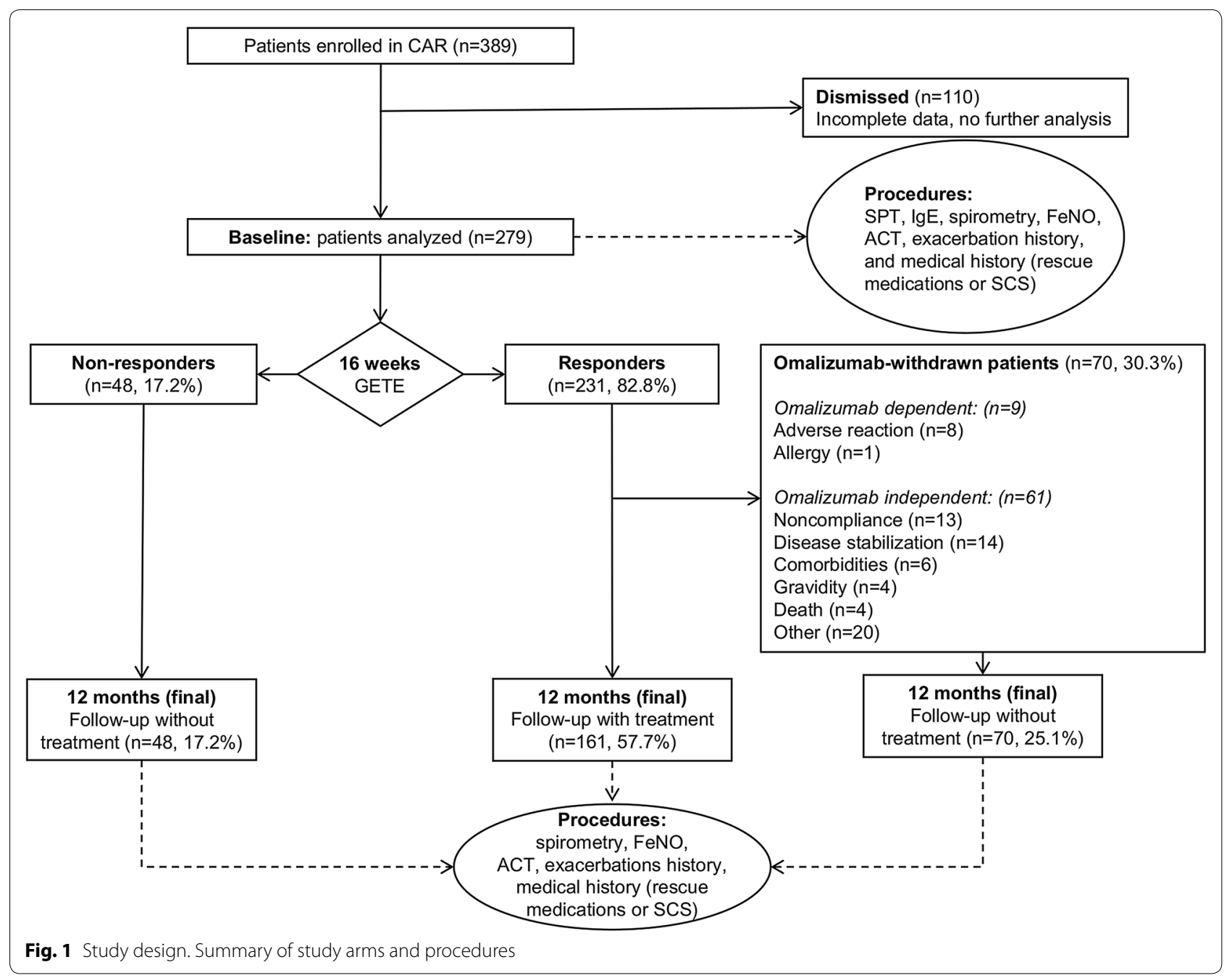

\section{Results}

\section{Baseline characteristics of patients}

Three hundred and eighty-nine patients with SAA treated with omalizumab as a part of a normal clinical practice were enrolled in the CAR in 10 specialized centers in the CR between 2007 and 2018. One hundred and ten patients ( $28.3 \%$ of all enrolled patients in the registry) were excluded from the assessment due to incomplete data in the registry. The data of 279 patients $(71.7 \%)$ who completed the study were analyzed, of which, $231(82.8 \%)$ were assigned as responders according to the GETE analysis results at 16 weeks after treatment initiation. Omalizumab treatment was further maintained only in responders. Both responders and non-responders were assessed 12 months after treatment initiation at the final point of study protocol. Seventy (30.3\%) responders withdrew treatment because of various reasons, including adverse events (AEs; $n=8)$, signs of allergy $(n=1)$, and non-AE reasons $(n=61$; noncompliance, disease stabilization, comorbidities, gravidity, death, administrative, and personal reasons). None of the AEs were assigned as severe. At the final study point (12 months after treatment deployment), the results of 161 (57.7\%) responders, 48 (17.2\%) non-responders, and 70 (25.1\%) patients who withdrew were compared (Fig. 1).

The baseline characteristics of patients in the three study arms did not significantly differ in terms of sex $(p=0.488)$, age $(p=0.274)$, weight $(p=0.452)$, total IgE $(p=0.186)$, or omalizumab dose $(p=0.772)$. Moreover, there were non-significant differences in FeNO $(\mathrm{p}=0.877)$ and FEV1 (\% of predicted, $\mathrm{p}=0.660$ ). However, non-responders had a significantly lower baseline ACT score (median 10 points) than responders and omalizumab-withdrawn patients (median 12 points for both, $p=0.005$ ). There were significant differences in the number of severe exacerbations during the year 


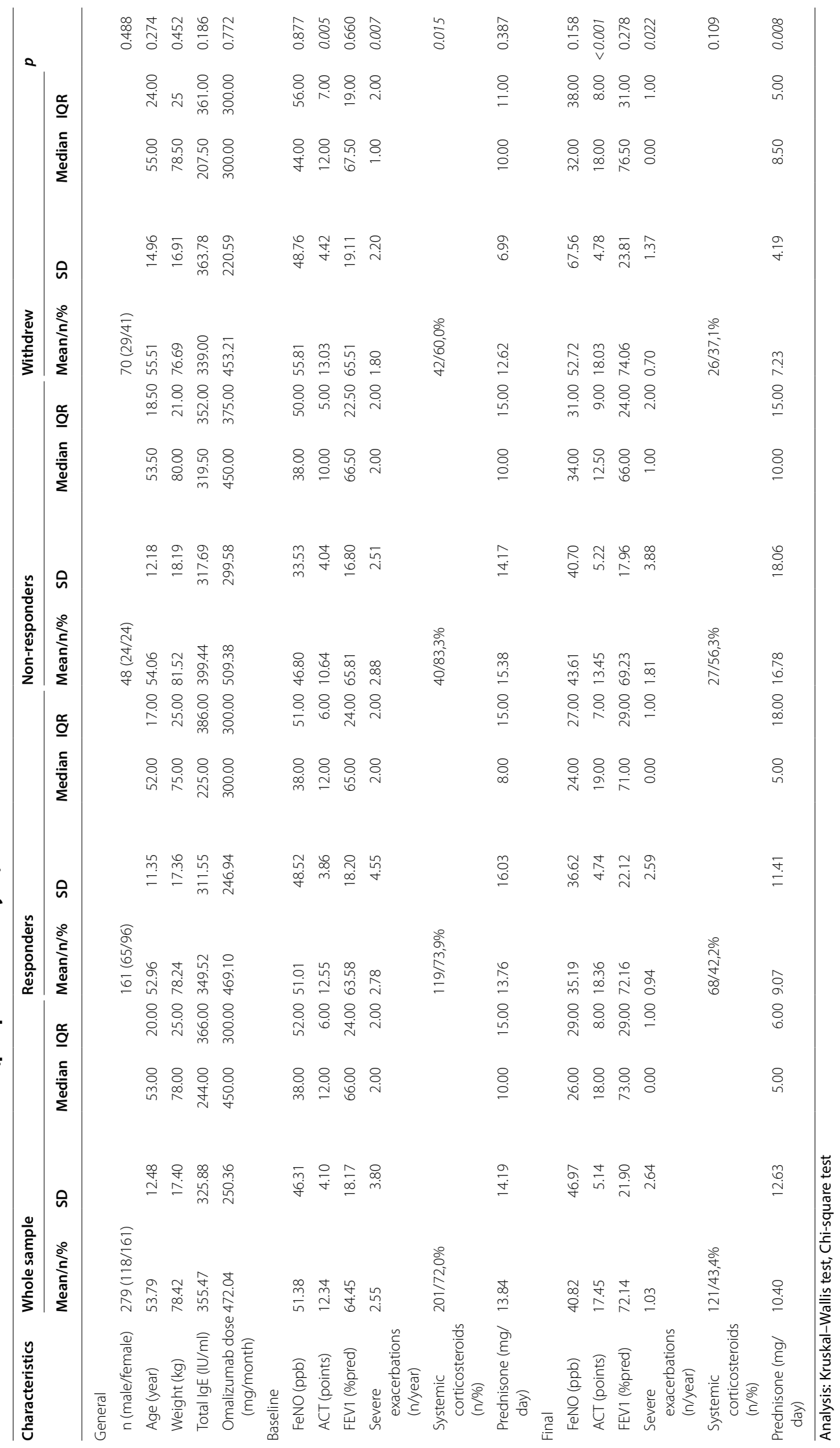




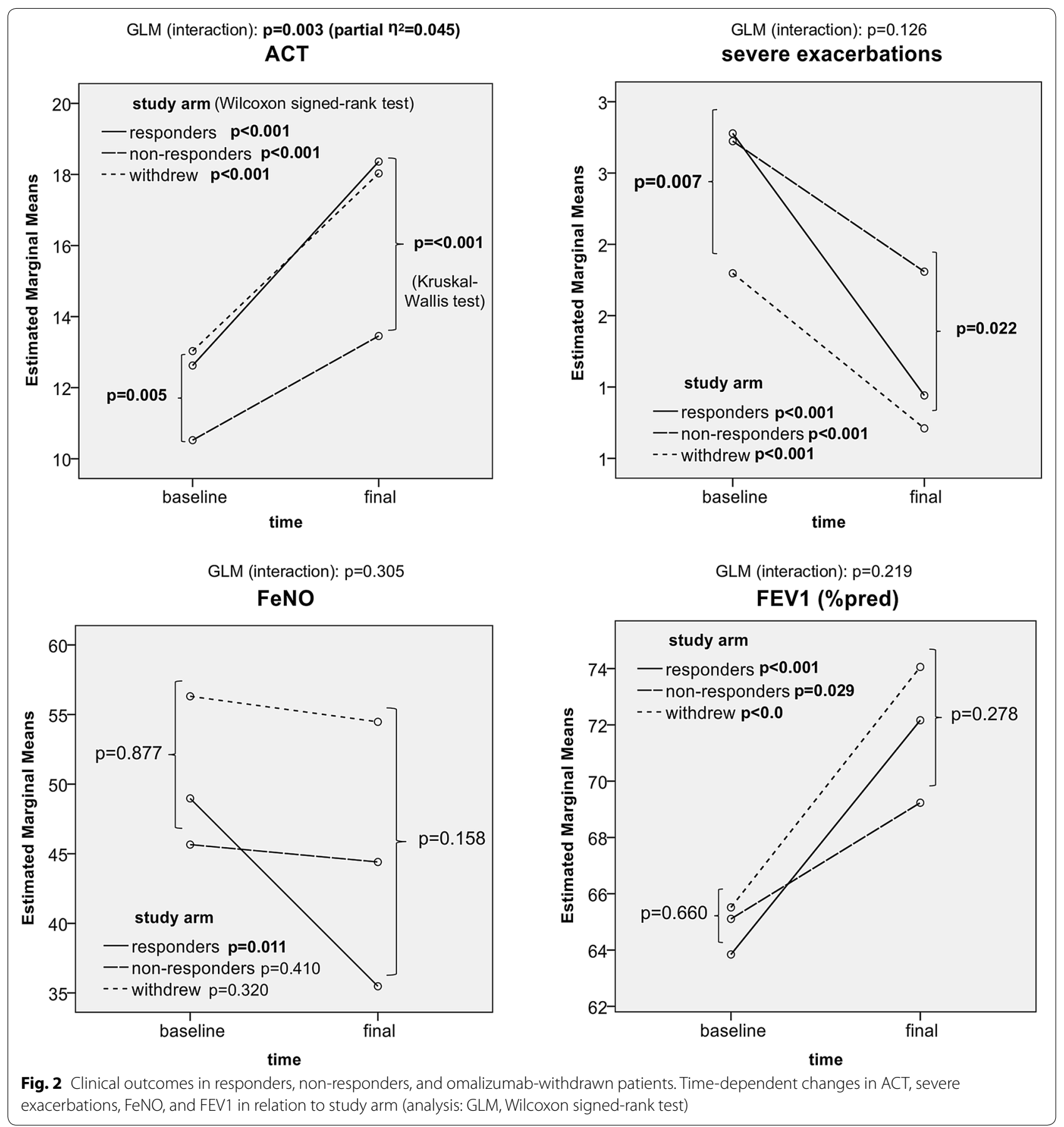

before treatment initiation. Both responders and nonresponders experienced a median of two exacerbations, whereas omalizumab-withdrawn patients had a median of one exacerbation $(p=0.007)$. The proportion of patients using SCS at the time of treatment initiation also differed significantly $(\mathrm{p}=0.015)$ in the three study arms: non-responders, 83.3\%; responders, 73.9\%; and omalizumab-withdrawn patients, $60 \%$. Nonetheless, the doses of SCS (equivalent to prednisolone) used in the three study arms were similar $(\mathrm{p}=0.387)$ (Table 2$)$.

\section{Time-dependent changes}

All measured parameters (ACT, annual rate of severe exacerbations, FeNO, FEV1, and SCS dose) improved during the 1-year treatment period in responders. In addition, a significant improvement was observed in 


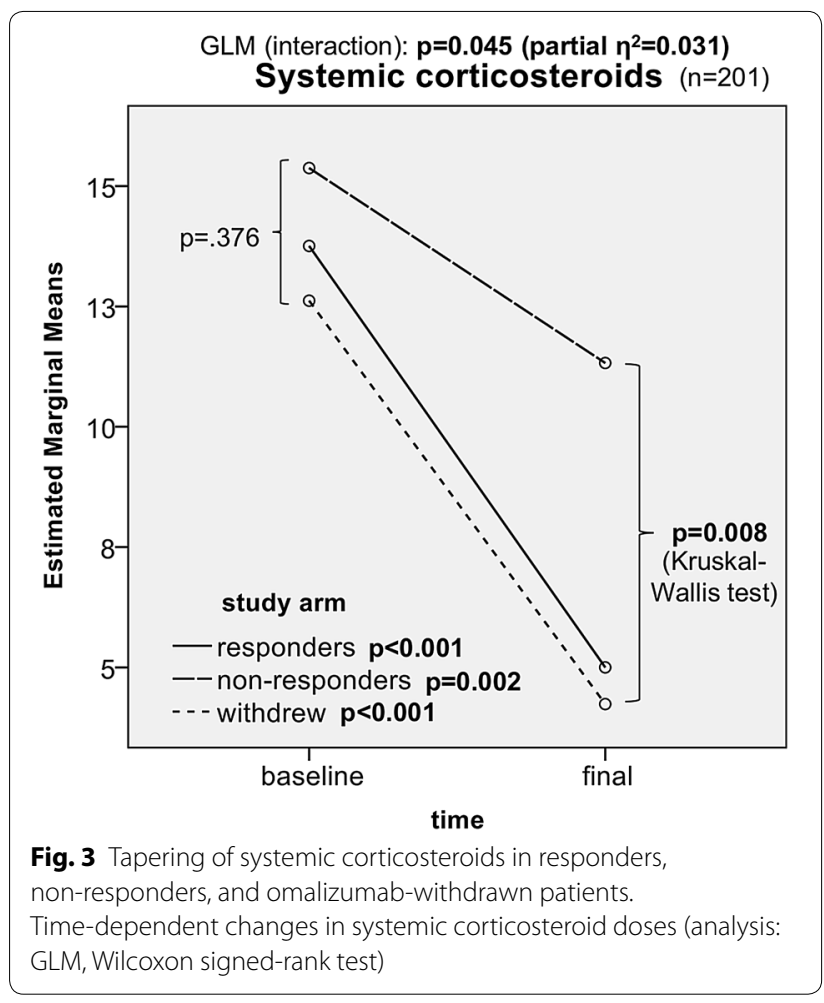

non-responders and omalizumab-withdrawn patients (excluding FeNO). The analysis of mutual interaction between the time factor and study arm factor presented significant results only for ACT score changes $(p=0.003$, partial $\left.\eta^{2}=0.045\right)$ and SCS dose reduction $(p=0.045$, partial $\eta^{2}=0.031$ ), with a rather low effect size (Fig. 2 and Table 2).

We also observed a substantial decrease in the proportion of patients using SCS in all the study arms. The most significant decrease was observed in the responder group (from $73.9 \%$ to $42.2 \%$ ); $42.3 \%$ of patients using SCS at baseline were allowed to discontinue the drugs, and only five patients initiated SCS during the study period de novo $(\mathrm{p}<0.001)$ (Figs. 3 and 4; Table 2).

\section{Sensitization characteristics}

We found no significant differences in the ratio of sensitization to particular perennial allergens or allergen groups among all study arms [assessed either semiquantitatively or dichotomously, $\mathrm{p}=0.249$, except for a concurrent sensitization to all tested perennial allergens (i.e., mites (Dermatophagoides pteronyssinus and/or D. farinae), molds (mixture of molds and/or Aspergillus spp. and/or Alternaria spp.), cats, and dogs)], and they were assigned to a polysensitized subgroup of patients. The highest proportion (72.5\%) of all polysensitized subjects was recruited from the responders arm (23\% of responders, $\mathrm{p}=0.043)($ Fig. 5 and Table 1 ).
No significant difference was observed in age, weight, total IgE, or omalizumab dose between the polysensitized and non-polysensitized responders (Table 3). The clinical characteristics of polysensitized patients were independent of wheal diameter or specific IgE levels to particular allergens. However, we observed some clinically relevant differences. Polysensitized patients in the responders study arm exhibited a lower tendency to improve the ACT result (a mean improvement of 6.41 points in non-polysensitized vs. 3.64 points in polysensitized subgroup, $\mathrm{p}=0.002$ ) and a lower tendency to reduce the annual number of exacerbations (a mean reduction of 2.15 in non-polysensitized subgroup vs. 0.81 in polysensitized subgroup, $\mathrm{p}=0.018$ ) compared with non-polysensitized patients (Fig. 8). This difference led to significant interactions between polysensitization and time-dependent changes in ACT and exacerbation rate (ER) reduction in the GLM-RM analysis $(p=0.001$, partial $\eta^{2}=0.066$ for ATC improvement and $p=0.044$, partial $\eta^{2}=0.027$ for ER reduction) despite nonsignificant differences between these two populations at particular study points (Figs. 6 and 7).

\section{Logistic regression}

We performed a meticulous logistic regression analysis of the influence of polysensitization on the odds of being a responder regarding a clinically significant improvement in the $\mathrm{ACT}$ result (i.e., $\geq 3$ points), a reduction in exacerbations (Fig. 8), an improvement in $\mathrm{FEV}_{1}$ (\% of predicted), a reduction in FeNO, and a reduction in SCS dose. A significant positive effect of polysensitization on odds of being a responder $(\mathrm{OR}=2.217, \mathrm{p}=0.02)$ and negative effect on odds of ACT improvement $(\mathrm{OR}=0.503, \mathrm{p}=0.032)$ were observed in the whole sample analysis. In other words, polysensitized patients exhibited a higher tendency to be a responder, but a lower tendency to increase ACT $\geq 3$ points than nonpolysensitized patients (Fig. 9, Table 4).

We obtained similar results in the sub-analysis of responders. Polysensitized responders revealed a lower tendency to improve the ACT result $(\mathrm{OR}=0.398$, $\mathrm{p}=0.023)$ and reduce $\mathrm{ER}(\mathrm{OR}=0.431, \mathrm{p}=0.034)$ than non-polysensitized patients.

\section{Discussion}

In the present study, we evaluated the effect of sensitization to individual allergens or their combinations on the outcomes of anti-IgE therapy in patients with SAA. Polysensitized patients showed a higher tendency to be a responder than non-polysensitized patients, and a lower tendency to increase ACT and reduce ER.

There is strong evidence to indicate that antiIgE therapy has an impressive immuno-modulatory 


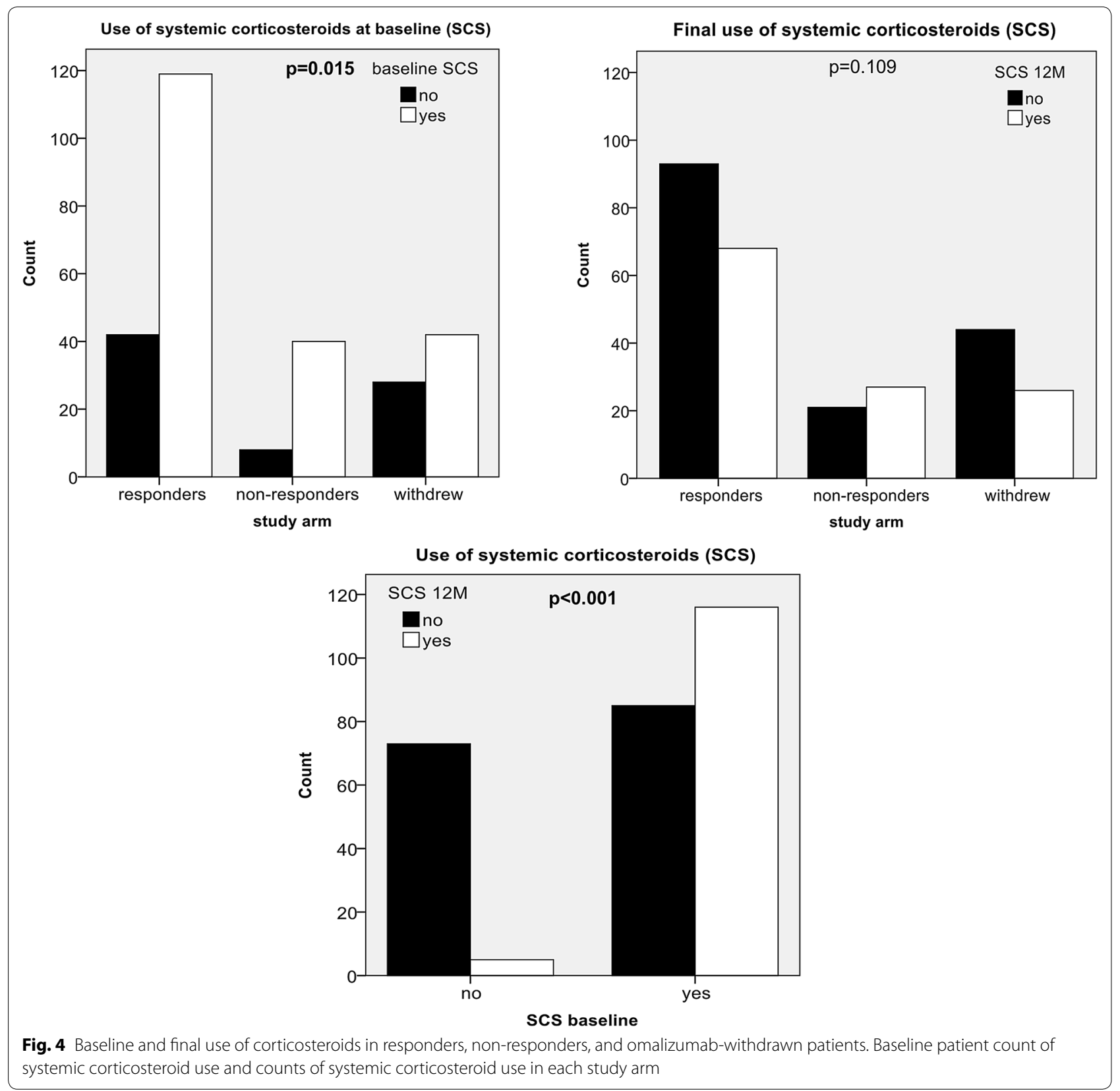

effect [30, 31] and broad clinical effects [31-33], notably a decrease in the daily dose of SCS or even its termination and an improvement in the quality of life, as documented in several real-setting studies [14]. There are also rare reports of the suppression of allergic reactivity [34-37] or susceptibility to viral infections by anti-IgE therapy [38]. Other studies on the clinical characteristics of patients have shown optimal clinical benefits of the treatment. The biomarkerbased prospective study EXTRA demonstrated that omalizumab treatment tends to be more effective in patients with elevated baseline eosinophil count, FeNO, and serum periostin level [39]. However, these results have not been confirmed in the retrospective real-life analysis of omalizumab-treated patients, the STELLAIR study, which showed a clinically significant effect irrespective of baseline eosinophil count [40]. Similar results have been reported by the prospective observational study PROSPERO, which reported that the effects of omalizumab (a reduction in ER and number of hospitalizations, and an improvement in $\mathrm{ACT}$ ) were independent of either baseline eosinophil 


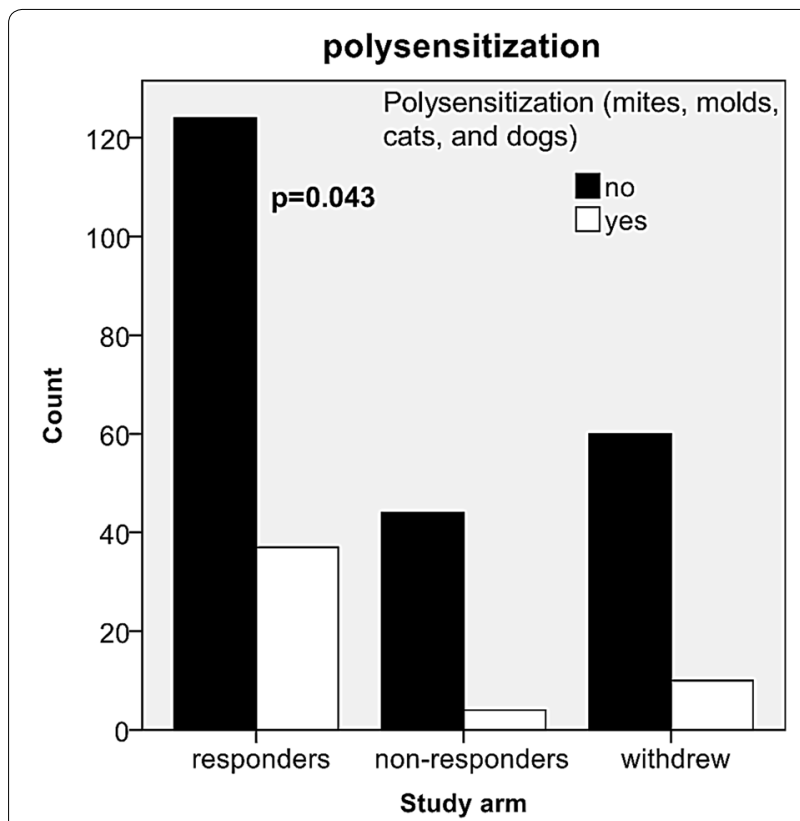

Fig. 5 Frequency of polysensitization in responders, non-responders, and omalizumab-withdrawn patients. Counts of patients with polysensitization in relation to the study arm count or FeNO [41]. We should be aware of instability of peripheral blood immune parameters over a year in patients with stable asthma [42].

Notably, evidence regarding the influence of sensitization profile on omalizumab treatment outcomes is scarce. Currently, it is broadly accepted that the frequency of sensitization in a population to a particular allergen depends on the climate or environment; different biological features of causal allergens can determine the different clinical traits of allergy [43]. However, there are only a few studies on the clinical characteristics of patients with asthma related to the sensitization profile. A previous study in a Chinese population demonstrated that sensitization to house dust mites was associated with increased severity of asthma [44]. In contrast, another study (in Spain) reported that sensitization to different allergens was not associated with significant differences in severity and control of asthma. However, diagnostic and therapeutic approaches slightly differ according to individual allergen sensitization [45]. Moreover, there was no mention of anti-IgE treatment.

In the CR, patients with severe uncontrolled asthma are treated in specialized sites of NCTA [46, 47]. Only these

Table 3 Polysensitization

\begin{tabular}{|c|c|c|c|c|c|c|c|c|c|}
\hline \multirow[t]{2}{*}{ Characteristic } & \multicolumn{4}{|c|}{ No polysensitization } & \multicolumn{4}{|c|}{ Polysensitization } & \multirow[t]{2}{*}{$p$} \\
\hline & Mean/n/\% & SD & Median & IQR & Mean/n/\% & SD & Median & IQR & \\
\hline \multicolumn{10}{|l|}{ General } \\
\hline n (male/female) & $124(50 / 74)$ & & & & $37(15 / 22)$ & & & & 0.981 \\
\hline Age (years) & 53.36 & 10.94 & 52.00 & 17.00 & 51.62 & 12.68 & 52.00 & 18.00 & 0.546 \\
\hline Weight (kg) & 77.64 & 17.23 & 75.00 & 24.50 & 80.27 & 17.88 & 80.00 & 27.00 & 0.385 \\
\hline Total lgE (IU/ml) & 328.83 & 294.71 & 204.50 & 377.00 & 418.84 & 358.10 & 304.00 & 444.00 & 0.178 \\
\hline Omalizumab dose (mg/month) & 483.87 & 247.80 & 450.00 & 300.00 & 419.59 & 240.74 & 300.00 & 300.00 & 0.109 \\
\hline \multicolumn{10}{|l|}{ Baseline } \\
\hline FeNO (ppb) & 51.26 & 50.23 & 38.00 & 48.00 & 50.14 & 42.93 & 38.00 & 59.00 & 0.891 \\
\hline ACT (points) & 12.19 & 3.68 & 12.00 & 5.50 & 13.73 & 4.23 & 14.00 & 7.00 & 0.065 \\
\hline FEV1 (\%pred) & 63.61 & 18.65 & 66.50 & 24.00 & 63.49 & 16.83 & 61.00 & 15.00 & 0.576 \\
\hline Severe exacerbations (n/year) & 2.98 & 4.89 & 2.00 & 3.00 & 2.08 & 3.14 & 1.00 & 1.00 & 0.080 \\
\hline Systemic corticosteroids (n/\%) & $97(78.2 \%)$ & & & & $22(59.5 \%)$ & & & & 0.023 \\
\hline Prednisone (mg/day) & 13.29 & 14.86 & 7.00 & 15.00 & 15.82 & 20.71 & 10.00 & 15.00 & 0.239 \\
\hline \multicolumn{10}{|l|}{ Final } \\
\hline FeNO (ppb) & 37.01 & 37.66 & 24.00 & 26.00 & 28.78 & 32.50 & 20.00 & 32.00 & 0.114 \\
\hline ACT (points) & 18.63 & 4.81 & 20.00 & 7.00 & 17.53 & 4.48 & 17.00 & 7.50 & 0.159 \\
\hline FEV1 (\%pred) & 72.43 & 23.14 & 76.00 & 30.00 & 71.31 & 18.71 & 68.50 & 22.50 & 0.560 \\
\hline Severe exacerbations (n/year) & 0.85 & 2.46 & 0.00 & 1.00 & 1.25 & 3.01 & 0.00 & 1.00 & 0.581 \\
\hline Systemic corticosteroids (n/\%) & $54(43.5 \%)$ & & & & $14(20.6 \%)$ & & & & 0.537 \\
\hline Prednisone (mg/day) & 7.94 & 8.95 & 5.00 & 8.00 & 13.43 & 17.87 & 5.00 & 5.00 & 0.308 \\
\hline
\end{tabular}

Baseline and final characteristics of responders with regards to polysensitization (per protocol analysis, Wilcoxon signed-rank test, and Chi squared test) 

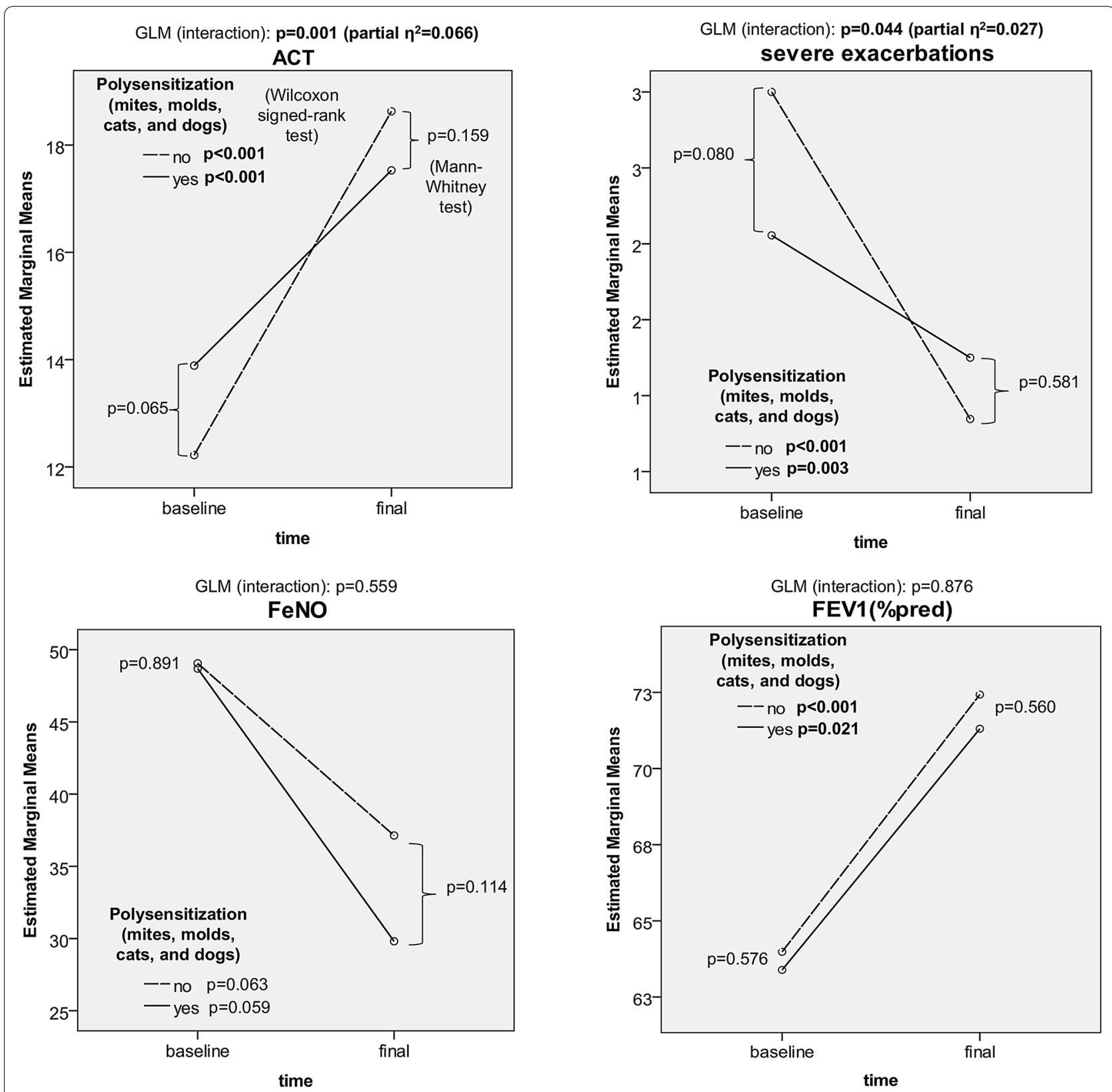

Fig. 6 Clinical outcomes in polysensitized and non-polysensitized patients. Time-dependent changes in ACT, severe exacerbations, FeNO, and FEV1 in relation to polysensitization at baseline (analysis: GLM, Wilcoxon signed-rank test)

centers are eligible to indicate biological treatment with anti-IgE antibody (omalizumab) in the CR [7, 47]. This careful approach may contribute to the higher number of responders (according to GETE) in the eXpeRience registry (88.9\%) [15] than in data from other countries $(69.9 \%)$ [48]. Extensive supervision of patients in the
NCTA centers can result in better treatment outcomes with respect to some parameters in all groups of patients.

In our analysis of patients, whose data are included in the CAR registry, we reported similar response rates according to the GETE analysis at 16 weeks after treatment initiation (82.8\%). However, the treatment 


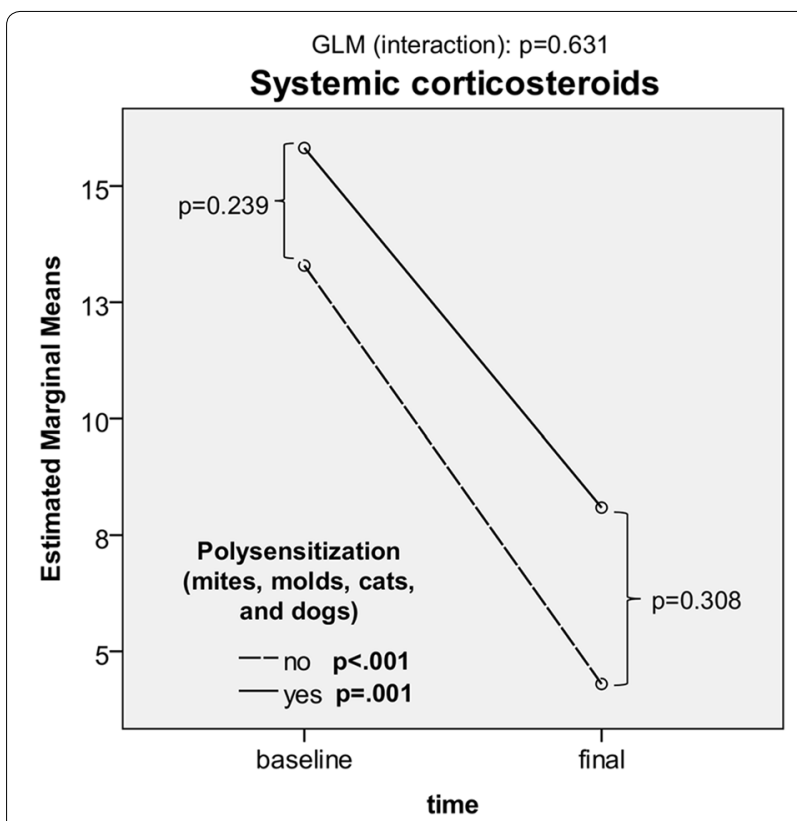

Fig. 7 Tapering of systemic corticosteroids in polysensitized and non-polysensitized patients. Time-dependent changes in systemic corticosteroid doses (analysis: GLM, Kruskal-Wallis test, Wilcoxon signed-rank test)

outcomes were remarkable in all groups of patients (including non-responders and omalizumab-withdrawn patients). This might be due to the fact that all patients were treated with omalizumab for at least 16 weeks (non-responders), 12 months (responders), and between 16 weeks and 12 months (omalizumab-withdrawn patients). Another reason could be the unequal number of patients in all study arms. In addition, there may be a bias in results of responders compared with that of omalizumab-withdrawn patients, because all patients in the withdrawn group were a subgroup of responders. Moreover, 14 patients (20\%) in this group discontinued treatment because of the stabilization of disease. Other reasons for withdrawal were diverse, but none of them was worsening of the disease. Although Namazy et al. $[49,50]$ proved that the use of omalizumab in pregnant women was safe, we preferred to terminate treatment by a mutual agreement with pregnant women in some centers. The outcomes were not influenced by the fact that non-responders appeared to have more severe disease than other patients (Table 2).

Lombardi et al. [43] reported that some aeroallergens, especially molds, pet dander, cockroach, and ragweed, were found to be more strongly associated with severe asthma. The association between mold sensitization and severe asthma is well known and conceptualized as severe asthma associated with fungal sensitization [51]. The identification of related causal allergen(s) is important for optimal complex therapeutic strategies,

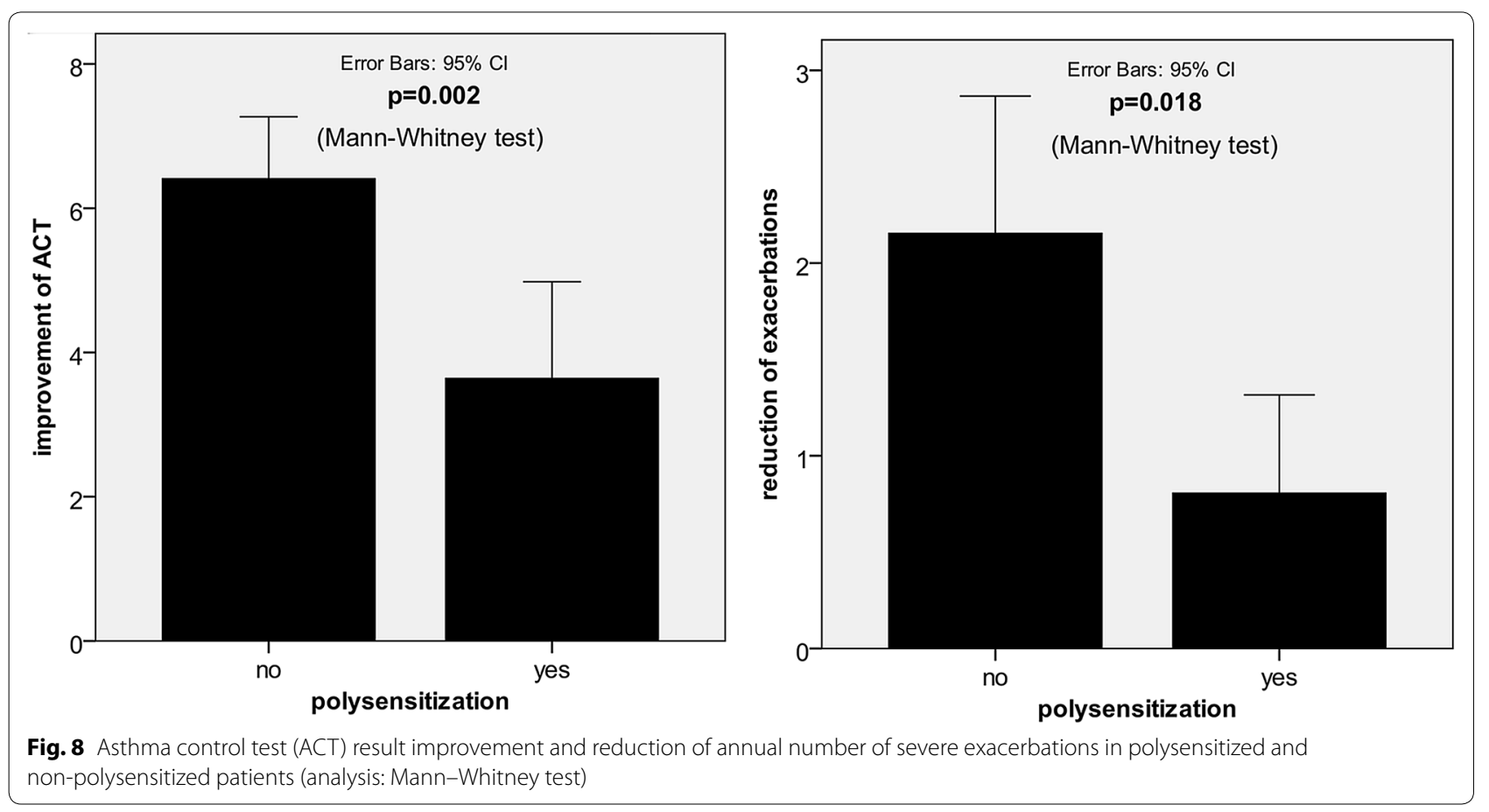


(See figure on next page.)

Fig. 9 Forest plot and odds ratio of selected variables in relation to polysensitization. OR of the selected outcome measures in relation to polysensitization at baseline (analysis: binary logistic regression)

including specific allergen immunotherapy [52]; however, evidence of allergen avoidance is under debate [53].

In our study, we assessed mites instead of cockroaches because the representation of patients with sensitization to cockroach in the Czech population is weak compared with that in other countries (e.g., the USA). In the subgroup of monosensitized or polysensitized patients, there was no significant difference in treatment outcomes regarding GETE (Table 1) and no difference in asthma severity. Nevertheless, polysensitized patients (as defined above) had higher odds ( $\mathrm{OR}=2.217, \mathrm{p}=0.02)$ of being responders than all other subgroups of nonpolysensitized patients. In contrast, they had reduced odds of ACT improvement $(\mathrm{OR}=0.503, \mathrm{p}=0.032)$ among all other subgroups $(\mathrm{OR}=0.398, \mathrm{p}=0.023$ in the responder subgroup) and a reduction in exacerbation $(\mathrm{OR}=0.431, \mathrm{p}=0.034$ in the responder subgroup) compared with the non-polysensitized patients. This can be explained by the tendency (although nonsignificant) of polysensitized patients to have a higher baseline ACT score and lower rate of severe exacerbations than nonpolysensitized patients. In addition, these patients tend to have a better clinical status at treatment initiation than non-polysensitized patients (Fig. 8). We suggest that these polysensitized patients with asthma may have a different subgroup of allergic diseases that may share some features with the "Th2-ultrahigh" concept suggested by Peters [54]. However, we do not have enough data to confirm this possible connection.

There were certain limitations to our study. First is the low number of patients with a distinct sensitization profile, which led to a loss of statistical power. However, a substantial number of patients from the initial pool $(\mathrm{n}=389)$ had to be excluded from the assessment $(n=110,28.3 \%$ of all enrolled patients in the registry) due to incomplete data in the registry. The used perprotocol analysis was not designed to treat censored (or missing) data. Second, we lost some information owing to the semiquantitative evaluation of categorized levels of sensitization. Third, we could not assess differences in treatment outcomes among patients sensitized to perennial or seasonal allergens (including weeds) because virtually all patients were concurrently sensitized to at least one (or mostly more) seasonal allergen and at least one (or more) perennial allergen, which was a necessary pre-condition for treatment initiation according to the omalizumab Summary of Product Characteristics. Fourth, there are some conflicting results regarding baseline ACT, an ER in responders; this could be caused only by sampling error. However, due to the exploratory nature of the study, we believe that it is important to remark all interesting data configuration to highlight potential variables for future confirmatory studies. Thus, we are unable to suggest a simple and clear clue to deal with the kind of sensitisation of patients with asthma receiving omalizumab therapy. We rather focused on seeking potential variables and parameters that could be used as putative biomarkers to estimate the supposed disease evolution and possible treatment outcomes. Finally, because of the observational nature of the study, we did not exploit randomization and placebo control group.

\section{Conclusions}

In summary, this is the first study to provide data on the effects of allergen sensitization of patients with allergic asthma on omalizumab treatment response. We believe that there may be some biological differences among distinct subpopulations of patients with asthma in terms of polyvalence of atopic sensitization. These differences may lead to distinct objective treatment effects (e.g., reduction in severe exacerbations) and different subjective disease perception (e.g., improvement in the ACT result).

We found that polysensitized patients exhibited a higher tendency to be responders than nonpolysensitized patients but a lower tendency of showing an improvement in the ACT results and a reduction in ER. We suggest that these polysensitized patients with asthma may constitute a separate subgroup of individuals with different allergic diseases and distinct clinical characteristics. Prospective data from controlled trials are needed to confirm these observations. 


\section{Effect of polysensitization (logistic regression)}

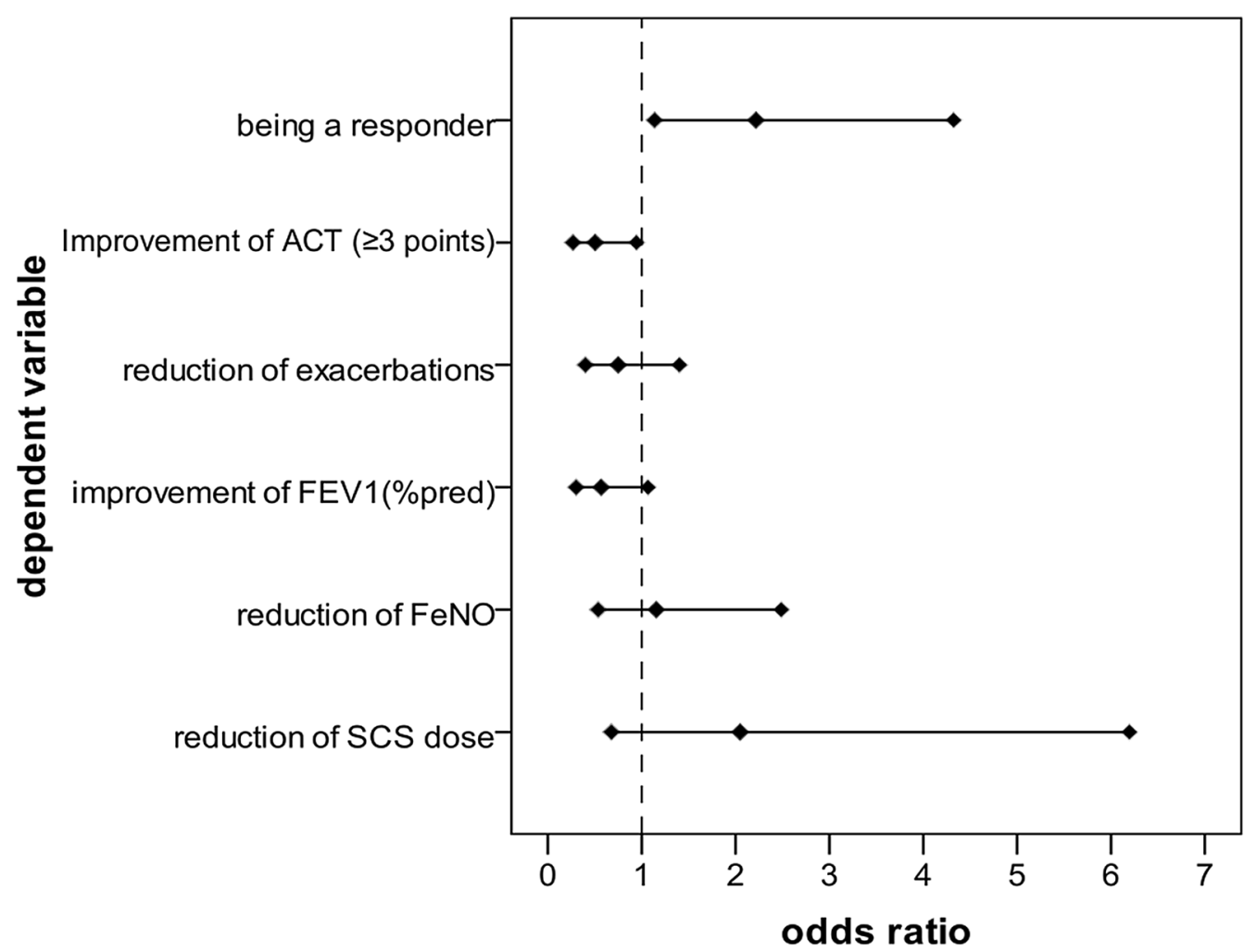

$\frac{5}{2}$
$\frac{0}{10}$
0
$\frac{0}{3}$
$\frac{0}{10}$

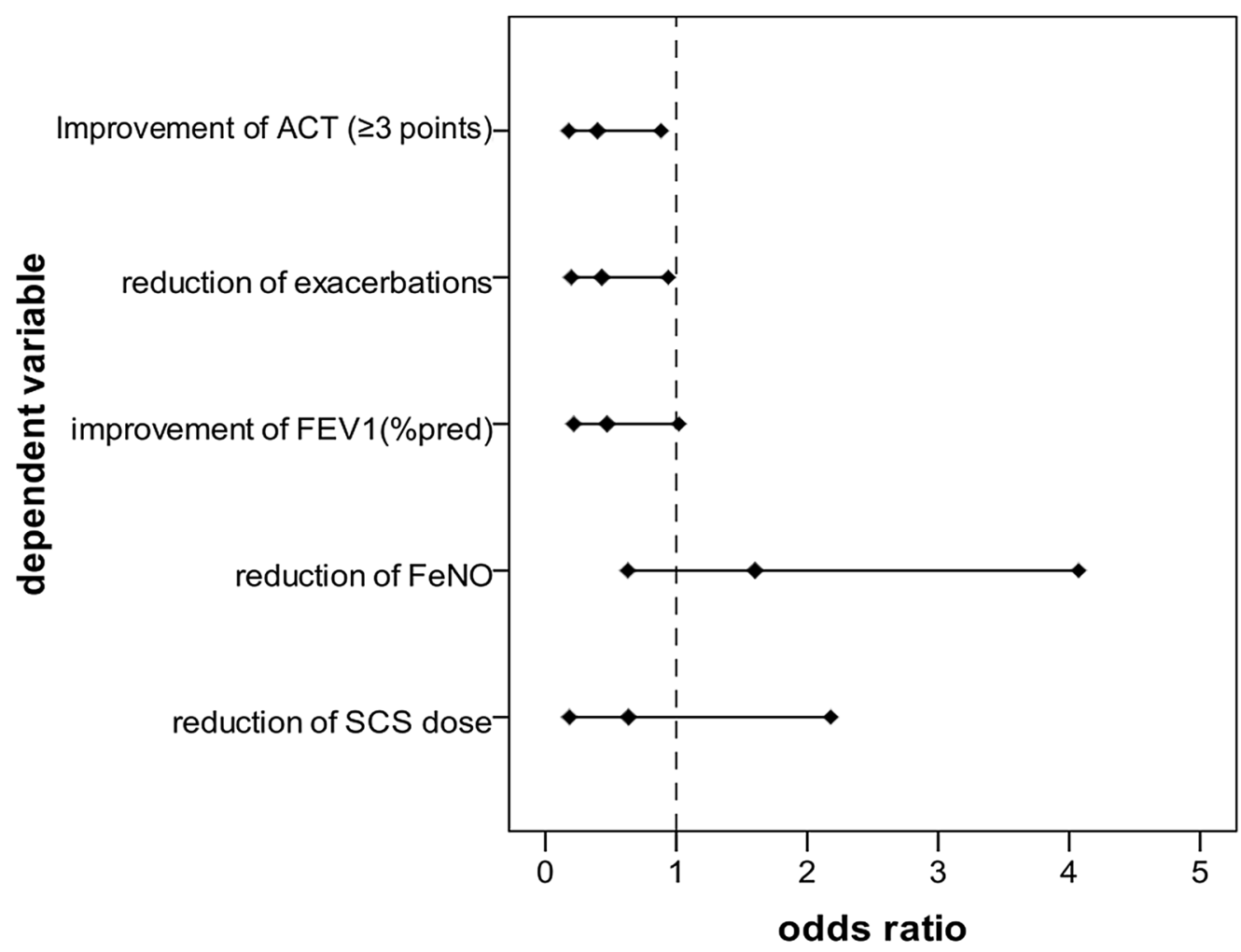

D
$\frac{\mathbb{D}}{0}$
$\frac{0}{2}$
$\frac{0}{D}$
$\frac{0}{\infty}$ 
Table 4 Binary logistics regression (effect of polysensitization)

\begin{tabular}{|c|c|c|c|c|c|c|}
\hline \multirow[t]{2}{*}{ Sample } & \multirow[t]{2}{*}{$\mathbf{n}$} & \multirow[t]{2}{*}{ Dependent variable } & \multirow[t]{2}{*}{ OR } & \multicolumn{2}{|c|}{$95 \% \mathrm{Cl}$ for OR } & \multirow[t]{2}{*}{$p$} \\
\hline & & & & Lower & Upper & \\
\hline Whole sample & 279 & Being a responder & 2.217 & 1.137 & 4.323 & 0.02 \\
\hline \multirow[t]{4}{*}{ Whole sample } & 279 & Improvement in $\mathrm{ACT}$ ( $\geq 3$ points) & 0.503 & 0.268 & 0.944 & 0.032 \\
\hline & & Reduction in exacerbations & 0.749 & 0.4 & 1.401 & 0.365 \\
\hline & & Improvement in FEV1 (\%pred) & 0.567 & 0.301 & 1.066 & 0.078 \\
\hline & & Reduction in FeNO & 1.155 & 0.536 & 2.486 & 0.713 \\
\hline All patients receiving SCS & 201 & Reduction in SCS dose & 2.048 & 0.677 & 6.196 & 0.205 \\
\hline \multirow[t]{4}{*}{ Responders } & 161 & Improvement in $\mathrm{ACT}$ ( $\geq 3$ points) & 0.398 & 0.179 & 0.883 & 0.023 \\
\hline & & Reduction of exacerbations & 0.431 & 0.198 & 0.938 & 0.034 \\
\hline & & Improvement in FEV1 (\%pred) & 0.471 & 0.217 & 1.019 & 0.056 \\
\hline & & Reduction in FeNO & 1.601 & 0.63 & 4.072 & 0.323 \\
\hline All responders receiving SCS & 119 & Reduction in SCS dose & 0.635 & 0.184 & 2.179 & 0.474 \\
\hline
\end{tabular}

Forest plot and OR with regards to poly sensitization

\section{Abbreviations}

ACT: Asthma control test; ER: Exacerbation rate; CAR: Czech Anti-lgE Registry; GETE: Global evaluation of treatment effectiveness; SCS: Systemic corticosteroid; SAA: Severe allergic asthma; NCTA: National Centre for Severe Asthma; FEV1: Forced expiratory volume in 1s; FeNO: Fraction of exhaled NO.

\section{Acknowledgements}

The authors acknowledge the following collaborators for their contributions to the CAR: Assoc. Prof. Jaromír Bystroň, Beáta Hutyrová, Lucie Heribanová, Jan Chlumský, Dagmar Kindlová, Jana Klosová, Bronislava Novotná, Prof. Petr Panzner, Prof. Petr Pohunek, Patricie Popelková, Vratislav Sedlák, Irena Starová, Prof. Martina Vašáková, Vernerová Eva, and Jaromír Zatloukal. The authors thank the Institute of Biostatistics and Analyses at the Faculty of Medicine and the Faculty of Science of the Masaryk University Brno, Czech Republic (IBA MU) for administration of the CAR database. We would like to thank Editage (https ://www.editage.com) for English language editing.

\section{Authors' contributions}

PV was responsible for patient care, data collection, study design, and manuscript preparation; JN was responsible for patient care, data collection, study design, statistical analyses, and manuscript preparation; OK substantially contributed to data acquisition, result interpretation, and manuscript preparation; IK was responsible for patient care and manuscript preparation; MT substantially contributed to study conception, design, and planning, and to result interpretation and manuscript drafting. All authors substantially contributed to revising the entire manuscript. All authors have reviewed the version of the manuscript submitted and agree with its content and submission. All authors read and approved the final manuscript.

\section{Authors' information}

PV is the head of the Department of Respiratory Diseases in Hospital České Budějovice. All authors are members of NCTA in the Czech Republic; they have years of experience in the treatment of patients with severe asthma and care for these patients on a daily basis. MT, IK, JN, and OK are leaders in the field of asthma research in the Czech Republic.

\section{Funding}

Not applicable.

\section{Availability of data and materials}

Not applicable.

\section{Ethics approval and consent to participate}

This study was approved by the institutional ethics committee of Hospital Ceske Budejovice (LEC, reference number: 106/18). Consent for participation was not required due to the retrospective nature of the study.

\section{Consent for publication}

Not applicable.

\section{Competing interests}

The authors declare that they have no competing interests.

\section{Author details}

${ }^{1}$ Department of Respiratory Diseases, B. Němcové 54, Hospital České Budějovice, a.s., Faculty of Medicine in Pilsen, Charles University, 37001 Prague, Czech Republic. ${ }^{2}$ Institute of Clinical Immunology and Allergy, University Hospital and Faculty of Medicine, Hradec Kralove, Czech Republic.

${ }^{3}$ Department of Pneumology and Phthisiology, University Hospital and Faculty of Medicine in Pilsen, Charles University, Prague, Czech Republic.

Received: 29 April 2020 Accepted: 31 August 2020

Published online: 15 September 2020

\section{References}

1. Fahy JV. Type 2 inflammation in asthma-present in most, absent in many. Nat Rev Immunol. 2015;15:57-65.

2. Woodruff PG, Modrek B, Choy DF, Jia G, Abbas AR, Ellwanger A, et al. T-helper type 2-driven inflammation defines major subphenotypes of asthma. Am J Respir Crit Care Med. 2009;180:388-95.

3. Terl M, Pohunek P, Kuhn M, Bystron J. Four seasons of Czech asthma study: asthma characteristics and management reality in the Czech Republic. J Asthma. 2019;1-13.

4. Robinson D, Humbert M, Buhl R, Cruz AA, Inoue H, Korom S, et al. Revisiting type 2-high and type 2-low airway inflammation in asthma: current knowledge and therapeutic implications. Clin Exp Allergy. 2017:47:161-75.

5. Coverstone AM, Seibold MA, Peters MC. Diagnosis and management of T2-high asthma. J Allergy Clin Immunol Pract. 2020:8:442-50.

6. Kuruvilla ME, Lee FEH, Lee GB. Understanding asthma phenotypes, endotypes, and mechanisms of disease. Clin Rev Allergy Immunol. 2019;56:219-33.

7. Terl M, Sedlák V, Cap P, Dvořáková R, Kašák V, KočíT, et al. Asthma management: a new phenotype-based approach using presence 
of eosinophilia and allergy. Allergy Eur J Allergy Clin Immunol. 2017;72:1279-87.

8. Chung KF, Wenzel SE, Brozek JL, Bush A, Castro M, Sterk PJ, et al. International ERS/ATS guidelines on definition, evaluation and treatment of severe asthma task force report ERS/ATS guidelines on severe asthma executive summary. Eur Respir J. 2014;43:343-73.

9. Bousquet J, Siergiejko Z, Świebocka E, Humbert M, Rabe KF, Smith N, et al. Persistency of response to omalizumab therapy in severe allergic (lgEmediated) asthma. Allergy. 2011;66:671-8.

10. Humbert M, Beasley R, Ayres J, Slavin R, Hébert J, Bousquet J, et al. Benefits of omalizumab as add-on therapy in patients with severe persistent asthma who are inadequately controlled despite best available therapy (GINA 2002 step 4 treatment): iNNOVATE. Allergy. 2005;60:309-16.

11. Deschildre A, Marguet C, Salleron J, Pin I, Rittié JL, Derelle J, et al. Add-on omalizumab in children with severe allergic asthma: a 1-year real life survey. Eur Respir J. 2013:42:1224-33.

12. Korn S, Thielen A, Seyfried S, Taube C, Kornmann O, Buhl R. Omalizumab in patients with severe persistent allergic asthma in a real-life setting in Germany. Respir Med. 2009;103:1725-31.

13. Barnes N, Menzies-Gow A, Mansur AH, Spencer D, Percival F, Radwan $A$, et al. Effectiveness of omalizumab in severe allergic asthma: a retrospective UK real-world study. J Asthma. 2013;50:529-36.

14. Kuprys-Lipinska I, Majak P, Molinska J. Effectiveness of the Polish program for the treatment of severe allergic asthma with omalizumab: a singlecenter experience. BMC Pulm Med. 2016;16:1-9.

15. Kirchnerová OR, Valena T, Novosad J, Teřl M. Real-world effectiveness and safety of omalizumab in patients with uncontrolled severe allergic asthma from the Czech Republic. Adv Dermatol Allergol. 2019;36:34-43.

16. EMA. Summary of product characteristics-Xolair 2018:1-33.

17. Domingo C, Pomares $X$, Navarro A, Rudi N, Sogo A, Dávila I, et al. Omalizumab is equally effective in persistent allergic oral corticosteroiddependent asthma caused by either seasonal or perennial allergens: a pilot study. Int J Mol Sci. 2017;18:521.

18. Pedersen SE, Bateman ED, Boulet L-P, Cruz AA, FitzGerald JM, Inoue H, et al. Global strategy for asthma management and prevention (2018 Update). 2018.

19. Milan Teřl A, Čáp P, Dvořáková R, Kašák V, KočíT, Novotná B, et al. Recommended procedure for diagnosis and treatment of asthma bronchiale. 1st ed. Geum. 2015.

20. Custovic A, Johnston SL, Pavord I, Gaga M, Fabbri L, Bel EH, et al. EAACI position statement on asthma exacerbations and severe asthma. Allergy. 2013;68:1520-31.

21. Bousquet J, Mantzouranis E, Cruz AA, Aït-Khaled N, Baena-Cagnani CE, Bleecker ER, et al. Uniform definition of asthma severity, control, and exacerbations: document presented for the World Health Organization Consultation on Severe Asthma. J Allergy Clin Immunol. 2010;126:926-38.

22. Reddel HK, Taylor DR, Bateman ED, Boulet LP, Boushey HA, Busse WW, et al. An official American Thoracic Society/European Respiratory Society statement: asthma control and exacerbations_-standardizing endpoints for clinical asthma trials and clinical practice. Am J Respir Crit Care Med. 2009;180:59-99.

23. Miller MR, Hankinson J, Brusasco V, Burgos F, Casaburi R, Coates A, et al. Standardisation of spirometry. Eur Respir J. 2005;26:319-38.

24. Measurement O. ATS/ERS recommendations for standardized procedures for the online and offline measurement of exhaled lower respiratory nitric oxide and nasal nitric oxide, 2005. Am J Respir Crit Care Med. 2005;171:912-30.

25. Dweik RA, Boggs PB, Erzurum SC, Irvin CG, Leigh MW, Lundberg JO, et al. An official ATS clinical practice guideline: interpretation of exhaled nitric oxide levels (FENO) for clinical applications. Am J Respir Crit Care Med. 2011;184:602-15.

26. Nathan RA, Sorkness CA, Kosinski M, Schatz M, Li JT, Marcus P, et al. Development of the Asthma Control Test: a survey for assessing asthma control. J Allergy Clin Immunol. 2004;113:59-65.

27. Schatz M, Sorkness CA, Li JT, Marcus P, Murray JJ, Nathan RA, et al. Asthma control test: reliability, validity, and responsiveness in patients not previously followed by asthma specialists. J Allergy Clin Immunol. 2006;117:549-56.
28. Bousquet J, Heinzerling L, Bachert C, Papadopoulos NG, Bousquet $P J$, Burney $P G$, et al. Practical guide to skin prick tests in allergy to aeroallergens. Allergy Eur J Allergy Clin Immunol. 2012;67:18-24.

29. Lloyd A, Turk F, Leighton T, Canonica GW. Psychometric evaluation of global evaluation of treatment effectiveness: a tool to assess patients with moderate-to-severe allergic asthma. J Med Econ. 2007;10:285-96.

30. Chanez P, Contin-Bordes C, Garcia G, Verkindre C, Didier A, De Blay F, et al. Omalizumab-induced decrease of FceRl expression in patients with severe allergic asthma. Respir Med. 2010;104:1608-17.

31. Froidure A, Mouthuy J, Durham SR, Chanez P, Sibille Y, Pilette C. Asthma phenotypes and IgE responses. Eur Respir J. 2016;47:304-19.

32. Ballow M, Akdis CA, Casale TB, Wardlaw AJ, Wenzel SE, Ballas Z, et al. Immune response modifiers in the treatment of asthma: a PRACTALL document of the American Academy of Allergy, Asthma \& Immunology and the European Academy of Allergy and Clinical Immunology. J Allergy Clin Immunol. 2012;130:311-24.

33. Kuhl K, Hanania NA. Targeting lgE in asthma. Curr Opin Pulm Med. 2012;18:1-5.

34. Varghese M, Lieberman P. The effects of repeat omalizumab administration on skin test positivity and the assessment of the safety of administration in patients with positive skin tests to mouse antigen. Allergy Asthma Proc. 2007;28:320-3.

35. Corren J, Shapiro G, Reimann J, Deniz Y, Wong D, Adelman D, et al. Allergen skin tests and free IgE levels during reduction and cessation of omalizumab therapy. J Allergy Clin Immunol. 2008;121:506-11.

36. Ong YE, Menzies-Gow A, Barkans J, Benyahia F, Ou TT, Ying S, et al. Anti-IgE (omalizumab) inhibits late-phase reactions and inflammatory cells after repeat skin allergen challenge. J Allergy Clin Immunol. 2005:116:558-64.

37. Yalcin AD. An overview of the effects of anti-lgE therapies. Med Sci Monit. 2014:20:1691-9.

38. Teach SJ, Gill MA, Togias A, Sorkness CA, Arbes SJ, Calatroni A, et al. Preseasonal treatment with either omalizumab or an inhaled corticosteroid boost to prevent fall asthma exacerbations. J Allergy Clin Immunol. 2015;136:1476-85.

39. Hanania NA, Wenzel S, Roseń K, Hsieh HJ, Mosesova S, Choy DF, et al. Exploring the effects of omalizumab in allergic asthma: an analysis of biomarkers in the EXTRA study. Am J Respir Crit Care Med. 2013;187:804-11.

40. Humbert M, Taillé C, Mala L, Le Gros V, Just J, Molimard M, et al. Omalizumab effectiveness in patients with severe allergic asthma according to blood eosinophil count: the STELLAIR study. Eur Respir J. 2018:51:1702523

41. Casale TB, Luskin AT, Busse W, Zeiger RS, Trzaskoma B, Yang M, et al. Omalizumab effectiveness by biomarker status in patients with asthma: evidence from PROSPERO, a prospective real-world study. J Allergy Clin Immunol Pract. 2019:7:156-64.

42. Shrestha Palikhe N, Bosonea A-M, Laratta C, et al. Stability of peripheral blood immune markers in patients with asthma. Allergy Asthma Clin Immunol. 2019;15:30.

43. Lombardi C, Savi E, Ridolo E, Passalacqua G, Canonica GW. Is allergic sensitization relevant in severe asthma? Which allergens may be culprit? World Allergy Organ J. 2017:10:2.

44. Li J, Huang Y, Lin X, Zhao D, Tan G, Wu J, et al. Influence of degree of specific allergic sensitivity on severity of rhinitis and asthma in Chinese allergic patients. Respir Res. 2011;12:95.

45. Domínguez-Ortega J, Quirce S, Delgado J, Dávila I, Martí-Guadaño E, Valero A. Diagnostic and therapeutic approaches in respiratory allergy are different depending on the profile of aeroallergen sensitisation. Allergol Immunopathol. 2014;42:11-8.

46. Sedlák V, Chlumský J, Teřl M, Novotná B, Král B. Recommended procedure for diagnosis and treatment of difficult to treat asthma. 2016.

47. Global Initiative for Asthma (GINA). Difficult-to-treat severe asthma in adolescent and adult patients GINA Pocket Guide for Health Professionals Diagnosis and Management. 2019.

48. Braunstahl GJ, Chen CW, Maykut R, Georgiou P, Peachey G, Bruce J. The eXpeRience registry: the "real-world" effectiveness of omalizumab in allergic asthma. Respir Med. 2013;107:1141-51.

49. Namazy JA, Blais L, Andrews EB, Scheuerle AE, Cabana MD, Thorp JM, et al. Pregnancy outcomes in the omalizumab pregnancy registry 
and a disease-matched comparator cohort. J Allergy Clin Immunol. 2020;145:528-36.

50. Namazy J, Cabana MD, Scheuerle AE, Thorp JM, Chen H, Carrigan G, et al. The Xolair Pregnancy Registry (EXPECT): the safety of omalizumab use during pregnancy. J Allergy Clin Immunol. 2015;135:407-12.

51. Agarwal R, Nath A, Aggarwal AN, Gupta D, Chakrabarti A. Aspergillus hypersensitivity and allergic bronchopulmonary aspergillosis in patients with acute severe asthma in a respiratory intensive care unit in North India. Mycoses. 2010:53:138-43.

52. Virchow JC, Backer V, Kuna P, Prieto L, Nolte H, Villesen HH, et al. Efficacy of a house dust mite sublingual allergen immunotherapy tablet in adults with allergic asthma. JAMA. 2016;315:1715-25.
53. Mclvor RA. Emerging therapeutic options for the treatment of patients with symptomatic asthma. Ann Allergy Asthma Immunol. 2015;115(265-271):e5.

54. Peters MC, Ringel L, Dyjack N, Herrin R, Woodruff PG, Rios C, et al. A transcriptomic method to determine airway immune dysfunction in T2-high and T2-low asthma. Am J Respir Crit Care Med. 2019;199:465-77.

\section{Publisher's Note}

Springer Nature remains neutral with regard to jurisdictional claims in published maps and institutional affiliations.
Ready to submit your research? Choose BMC and benefit from:

- fast, convenient online submission

- thorough peer review by experienced researchers in your field

- rapid publication on acceptance

- support for research data, including large and complex data types

- gold Open Access which fosters wider collaboration and increased citations

- maximum visibility for your research: over $100 \mathrm{M}$ website views per year

At BMC, research is always in progress.

Learn more biomedcentral.com/submissions 